\title{
CHRONICLE
}

\section{The People's Republic of China's Strategic Goals for Higher Education: 1991-2000}

The People's Republic of China's document on the outline of the Ten-Year Programme (1991-2000) and the Eighth Five-Year Plan (1991-1995) for national economic and social development was released in Beijing in January 1991.

The document stressed that, firmly following the road of building socialism with Chinese characteristics, was the fundamental guarantee for attaining the strategic objective of quadrupling 1980 's gross national product by the end of this century.

Parts of the important principles of the long-term programme are to actively develop a socialist-planned commodity economy, to combine planning with market regulation and promote a sustained, stable and coordinated development of the economy, and to constantly raise the ideological and ethical standards and scientific and cultural levels of the whole nation.

In order to achieve the above-mentioned objectives, the People's Republic of China will pay more attention to further developing and reforming its education in the coming decade. The relevant excerpt from the text of the document is as follows:

The People's Republic of China is to establish in the next decade an educational system with Chinese characteristics, which is geared to the twenty-first century.

The document states that this would be achieved by deepening China's educational reform, readjusting and optimizing the educational structure, raising the quality of education and the efficiency of schools, and strengthening the ranks of teachers. By the end of this century, the majority of the newly added labour force in rural areas will have received vocational education or technical training, and new workers in the enterprises must receive education before working and must undergo on-the-job training.

Statistics show that there are 1,075 institutions of higher learning in the People's Republic of China, with 2.06 million students.
The document notes that the scale of university and postgraduate education should be maintained as it is, with improvements to be made in the Eighth Five-Year Plan period. Specialized education should be expanded appropriately according to the needs and possibilities, and a number of key branches of learning should be established in accordance with actual need.

Doctoral students should be trained mainly at home, the document says, adding that the policy of sending students abroad for academic studies should be continued and improved, and international exchanges and cooperation further promoted.

The People's Republic of China's institutions of higher learning will strengthen the development of its science and technology, and some of the achievements will approach or reach advanced international levels. They will undertake the following tasks in developing science and technology in the coming decade.

- Launch scientific and technological task projects focusing on key areas concerning the modernization of production technology and equipment in industry and agriculture, population control, and protection of the ecological environment.

- Strengthen applied scientific research and popularize on a large scale scientific and technological achievements.

- Keep abreast of the new technological revolution and try to make fresh achievements in a few hi-tech fields.

- Strengthen basic scientific research, step up the construction of key and specialized laboratories and promote the integration of natural and social sciences.

The document calls for vigorous efforts to develop adult education and wipe out illiteracy. It sets a goal of eliminating illiteracy among young and middle-aged people across the country by the year 2000 . A recent survey shows that there are 180 million people in the People's Republic of China who are illiterate. 